Revista de Lenguas para Fines Específicos

\title{
A Corpus-based Study of I am thinking in Political Speeches
}

\author{
Montserrat Martínez Vázquez ${ }^{1}$ \\ Universidad Pablo de Olavide \\ Departamento de Filología y Traducción, Carretera de Utrera, km. 1 - 41013 Sevilla, Spain
}

\section{Article history \\ Paper received: 05 July 2018 Paper received in revised form and accepted for publication: 21 October 2018}

\section{Keywords}

progressive, I am thinking, interpretative progressive
ABSTRACT

This paper examines the occurrence of I am thinking in political speeches as opposed to general discourse. This combination containing a verb traditionally considered incompatible with the progressive seems to be evolving and extending its range of functions. Data drawn from a reference corpus of British English shows that I am thinking serves a wide array of discursive functions, besides its basic propositional cogitate meaning (parenthetical, filler, narrative and interpretative). In political speeches the construction has developed an almost exclusive cohesive role, i.e. the speaker's clarification of a previous utterance. This use, which derives from the interpretative progressive, is not available with the simple form, I think, a phrase extensively studied in the past decades as an epistemic unit with dissimilar functions in different types of discourse (Simon-Vandenbergen 2000). This analysis, furthermore, makes an important contribution to the understanding of the progressive as a marker of contingency (Goldsmith \& Woisetschlaeger 1982; De Wit \& Brisard 2014), highly interpretable in a situational or linguistic context.

\section{Introduction}

A considerable amount of literature has been published on the versatile phrase I think (e.g. Urmson 1952; Jucker 1986; Thompson \& Mulac 1991; Traugott 1995; Aijmer 1996, 1997; Kärkkäinen 2003; Simon-Vandenbergen 1998, 2000; Brinton 2008; Kaltenböck 2009; Van Bogaert 2010, 2011). These studies have examined it as a result of grammaticalisation (e.g. Traugott 1995; Thompson \& Mulac 1991; Kärkkäinen 2003; Van Bogeart 2006; Brinton 1996, 2008), incomplete pragmaticalisation (Aijmer 1997) or constructional grammaticalisation (Van Bogeart 2010, 2011). The different labels used to refer to this construction give a good account of its versatility: 'parenthetical' (Urmson 1952); 'epistemic parenthetical' (Thompson \& Mulac 1991); 'modal particle' (Aijmer

\footnotetext{
Corresponding author·Email: mmarvaz@upo.es
} 
1997); 'comment clause' (Brinton 2008; Kaltenböck 2009); and 'discourse marker' (Kärkkäinen 2003), among other terms. Moreover, this combination has been reported to show different behaviour across genres. Thus, Aijmer (1996) observes that in informal face-to-face conversation it typically expresses tentativeness or uncertainty (85\% in the London-Lund Corpus), while Simon-Vandenbergen $(1998,2000)$ indicates that in political interviews it denotes deliberation rather than tentativeness, 'authority rather than hesitation' (SimonVandenbergen 2000, p. 60).

The abundant literature on I think contrasts with the scant attention paid to its progressive form, I am thinking (hereinafter IAT). This construction has not been the object of a monographic study, as far as I know. It has been mentioned either as an instance of the 'special' uses of the progressive with stative verbs (e.g. Leech 2004, p. 29; Levin 2013) or as a variant of the epistemic unit I think (Karkkainen 2003; Bogaert 2010, 2011). This lack of interest in IAT is probably justified by its low productivity. Van Bogaert's $(2010,2011)$ random sample of think (180 tokens), extracted from the British National Corpus, did not yield any examples of IAT, and Karkkainen (2003) only found eleven tokens in the Santa Barbara Corpus of Spoken American English. Levin (2013) corroborates the low productivity of the progressive with think (in all personal forms and different tenses), although his data reveals an increasing tendency (66 progressive forms of think in the 1920s, 181 in the 1960s and 210 in the 2000s), which evinces an ongoing evolution.

Given the rich versatility and dissimilar behaviour across genres reported on I think, a construction particularly common in political discourse, my aim here is to analyse the functions and distribution of its progressive form in political discourse, in which the simple form is particularly common, as compared with its use in nonspecialised discourse. Considering the contingent meaning supplied by the progressive (Goldsmith \& Woisetschlaeger 1982; De Wit \& Brisard 2014), which makes it highly interpretable in context, it is hypothesised that genre should play an important role in the use and distribution of IAT. In order to test this hypothesis, I will examine the functions of this construction in a multigeneric corpus of contemporary British English, before contrasting them with their use in British political speeches.

The rest of this paper is organised as follows. Section 2 offers a brief review of the literature on the functions of the progressive and its occurrence with stative verbs, more specifically with think. Section 3 is concerned with the study methodology. The Section 4 presents and discusses the findings in two parts. The first part analyses the data extracted from a corpus of general discourse and provides a classification of the different uses of IAT; and the second explores the use of IAT in political speeches. Finally, the conclusion provides a brief summary of the findings and identifies limitations and areas for future research.

\section{Literature Review. The progressive}

Although the progressive (be $+\mathrm{V}$-ing) has been traditionally defined in aspectual terms ('action in progress', e.g. Quirk et al. 1985, p. 197; Biber et al. 1999, p. 460; Huddleston \& Pullum 2002, p. 163; Downing \& Locke 2006, p. 373), a considerable number of non-aspectual senses have also been identified: tentativeness, emotion, intensity, politeness and interpretation (e.g. Ljung 1980; Goldsmith \& Woisetschlaeger 1982; Smitterberg 2005; Kranich 2010, pp. 202-225; De Wit \& Brisard 2014, pp. 82-86). Many researchers eventually adopt a 'multiplicity of uses' approach to the progressive, given the difficulty of identifying a single meaning for a category used 'to emphasise contextually defined temporal reference' (Scheffer 1975, p. 388). This high dependency on contextual information is intrinsic to the notion of 'contingency' which has cropped up in different reports on the progressive. For example, Goldsmith and Woisetschlaeger $(1982$, p. 81) describe the non-aspectual uses of the 
progressive as denoting a 'phenomenal description of the world, in opposition to the non-progressive forms which report knowledge of the structure of the world'. Their description is in line with Calver (1946, p. 317) who described the present progressive as the 'tense of mere occurrence', in contrast to the simple present, which denotes the 'constitution of things'. Comrie (1976, p. 49 n.1) also suggests that the progressive may express a 'contingent situation', i.e. a situation which is 'not the normal state of things', although he acknowledges that this description does not cover other idiosyncratic uses of the progressive. Leech (2004, p. 20) views the limited duration denoted by the progressive as the expression of a 'situation subject to change'. Williams (2001) also finds this 'susceptibility to change' component in the progressive. More recently, De Wit and Brisard (2014) have integrated all these partial descriptions into one unifying framework; they claim that all the uses of the present progressive arise from a contingent core meaning, 'epistemic contingency' or 'non-necessity in the speaker's conception of current reality', in contrast to the simple form, which denotes 'structural necessity' (De Wit \& Brisard 2014, p. 50). Martínez Vázquez' s (2018) large corpus-based analysis of the progressive construction with love confirms that although the simple forms of love may occasionally denote non-structural situations, the progressive counterparts unquestionably designate phenomenal situations with variable interpretations arising in the context.

\subsection{Stative Progressives}

The progressive is increasingly extending to the so-called 'stative' verbs, traditionally described as not taking the progressive or only in 'special' cases (Leech 2004, p. 28 ff.). Stative verbs show different degrees of acceptance of the progressive; when they allow it, they typically undergo a change of meaning. For example, Huddleston and Pullum (2002, p. 170) distinguish four different active meanings of cogitate verbs in the progressive:

- As a dynamic cogitate verb (Don't interrupt me when I'm thinking).

- Expressing limited duration (I'm thinking we ought to accept).

- Offering an interpretation, explanation or comment on a previous utterance (He's not realising what he's saying).

- Expressing tentativeness (politeness) (I'm hoping you can help me).

The verb think is the most prototypical member of the class of mental state predicates (Nuyts 2001, p. 109). Its polysemous nature extends from the expression of a stable structural mental state, I think = my opinion is (Leech 2004 , p. 27), to express the 'ACTIVATION or AROUSAL of thought processes', as in I'm thinking for the moment in plain economic terms, where the verb denotes 'a kind of work or mental exertion, equivalent to "considering" or "ruminating"' (Leech 2004, p. 29, emphasis in the original).

Nuyts (2001, pp. 113-122) distinguishes between a qualificational and a non-qualificational meaning of mental predicates. The latter involves either 'being in mental state $X$ ' or 'performing mental process $X$ '. This nonqualificational use is the original meaning and appears in intransitive patterns (Shut up, I am thinking), with of or about (I am thinking of going home today) or introducing a quote (I thought: 'Oh no! Not again'). The qualificational use involves the speaker's evaluation of the current state of affairs. It occurs with a that or thatless clause (I think (that) they have run out of fuel) or as a parenthetical (It is dangerous to run out of fuel in a desert, I think). Nuyts (2001, p. 134) argues that in its qualificational use, think involves 'a momentaneous state of mind', which would be incompatible with the progressive. However, he acknowledges a marginal use ( $\mathrm{am}$ thinking that they might have run out of fuel) where the progressive is used as an 'epistemic weakener 
("progression" metaphorically standing for "uncertain with a tendency towards the positive")'. Levin (2013, p. 211) acknowledges this 'hedged' variant use (I am thinking that may be the Republicans are blowing this up a little bit...), although no examples of this 'inert cognition' think occurred in his Time sample. He identifies four main meanings of progressive think in the data extracted from his Time corpus:

- Cogitate: Stephens, aggrieved, had been thinking the same thing.

- Intend: Mom, I'm thinking of joining a cult and want to leave it everything in my will.

- Quotative: 'I was thinking, Man, this is normal?' says Danielle.

- Interpretative: When he said that stringent water-pollution standards would hinder industry, he was again thinking of Alaska and its abundance of clear rivers. Levin (2013, p. 210)

The cogitate and intended meanings are more frequent, although his data reveal a growing tendency to use the more subjective quotative and interpretative progressives.

Among the uses of the 'cogitate' sense, Levin (2013) mentions an emphasis or intensification of the action (These days his tone is quieter and more autumnal than it used to be; he is thinking hard about old age, Time; 02/12/1967), and the expression of temporariness (I am thinking of a series of disguises for myself, Time; 22/04/1929). The intended meaning, according to Levin (2013), typically comprises an idea of tentativeness relating to the notion of susceptibility to change (as in Williams 2002), which allows speakers to present future intentions in a hedged way (p. 212). The more colloquial quotative use is portrayed as 'puzzling', in line with Biber et al. (1999), with 'a more vivid imagery and a greater sense of involvement' (Biber et al. 1999, p. 475). This sense of involvement is evident in the case of IAT, since the speaker is also the experiencer. The quotative use is much more frequent in conversational discourse. In fact, Kärkkäinen (2010, p. 101 n. 10) observes that I thought, I'm thinking and I was thinking 'occur almost exclusively' with this function in the Santa Barbara Corpus of Spoken American English, 'where a speaker is acting as a narrator and quoting his/her own thoughts and opinions on the narrated incident'. She considers these phrases 'mental constructs' which involve a certain degree of mental activity, in contrast to I think, which lacks a cogitative sense in most of her corpus examples.

Another enigmatic non-aspectual function of the progressive is its interpretative use. This function has especially attracted the attention of scholars (Ljung 1980; Wright 1994; Huddleston \& Pullum 2002, p. 165; Leech 2004, p. 22; Smith 2005; Smitterberg 2005, pp. 207-241; Kranich 2009; Smith \& Leech 2013; Levin 2013; Kirk 2015, among others). In contrast to the simple form, the progressive may serve an explanatory function; 'the event described has an interrelationship or identity with another simultaneous event', as in Do you think he was telling the truth (when he said that)? (Quirk et al.1985, p. 198, n.b). This function is usually discussed in reference to verbs of communication, but thinking is also part of any speech act. In fact, Leech (2004) notes that the interpretative use offers 'the mental attitude or communicative intention lying behind the utterance' (Leech 2004, p. 22, emphasis mine).

Although this explanatory function of the progressive is intuitively very clear, there is no consensus on its categorisation which in itself is difficult (Smitterberg 2005, p. 229; Smith 2005, pp. 165-200). Besides this lack of agreement on the concept, Aarts et al. (2010, p. 162) also point out the difficulty of distinguishing this meaning in specific examples. As a result, the construction is often grouped with other non-aspectual uses under the rubric of 'special uses' (Wright 1995, p. 468).

After an extensive review of different approaches to the interpretative progressive, Smith and Leech (2013, p. 
91) - drawing mainly on König $(1980,1995)$ and Ljung (1980) - summarise six defining features (part A being the interpreted (mentioned or understood) part, and part B the interpretation (as proposed in Ljung 1980)):

(a) Part $B$ redescribes part $A$, giving it a deeper significance.

(b) $A$ and $B$ are construed as simultaneous.

(c) Subjects in parts A and B are coreferential.

(d) $A$ and $B$ appear in a syntactic frame, e.g. In saying/doing $A, X$ was (really) saying/doing B (König 1980).

(e) Subjects of $A$ and $B$ are agentive.

(f) B contains a speech-act (illocutionary) verb (Smith \& Leech 2013, p. 91).

According to Smith and Leech (2013), only the first two are obligatory. Moreover, part A is not always explicitly stated, as observed by Smitterberg (2005, p. 239); most of his corpus examples did not include the interpreted situation in a subordinate clause, which appeared either in an independent clause or was contextually inferred. He also points out that the interpretation may be of a negative nature ( $\mathrm{am}$ not imputing it as the least blame to this gentleman); hence, 'an interpretation is excluded rather than invited' (Smitterberg 2005, p. 232).

As regards productivity, Smitterberg (2005, pp. 231-232) reports an increase of interpretative progressives over the nineteenth century, although he cautions that prior use might be concealed by the limited access to historical texts containing dialogues, where interpretative uses are more abundant. In speech-based genres (debates, drama, trials and dialogue in fiction) they 'are frequently used to call attention to what has been stated in a previous turn of speech, in order either to re-interpret or to clarify what has been said'. He explains that speeches contain less interpretatives because they are 'monologic in nature' (Smitterberg, 2005, p. 232, n. 22). As regards written texts, Levin (2013) found a low rate of interpretative progressives in his Time corpus sample: no tokens in the 1920s, two in the 1960s and eight in the 2000 period.

What follows is a description of the empirical analysis of IAT in general and specialised language.

\section{Data and method}

The data for this study were drawn from two corpora of British English: the multi-generic British National Corpus (BNC) and the specialised British Parliament Corpus (Hansard) (see Table 1).

The BNC contains 100 million words of samples of written (90\%) and spoken (10\%) language from a wide range of registers (Spoken, Fiction, Magazine, Newspaper, Non-Academic, Academic and Miscellaneous) produced during the late twentieth century. This reference corpus of British English provides the baseline for this study. For political discourse, I used Hansard, which contains almost all the speeches delivered in the British Parliament from 1803 to 2005 (1.6 billion words). Although I extracted all the instances of IAT from Hansard, I limited the qualitative analysis to the last decade contained in the corpus (1985 to 1995).

Hansard resorts to Davie's software, which was also used to explore the BNC. I ran searches for both the contracted (I'm thinking) and non-contracted (I am thinking) forms. Some of the reference numbers in the examples extracted from Hansard had to be manually removed. 


\begin{tabular}{lllccc}
\hline corpus & \multicolumn{2}{c}{ genres } & date & texts & tokens \\
\hline BNC & Multi- & Spoken, Fiction, Magazine, Newspaper, Non- & $1980-1993$ & 4,049 & $98,363,783$ \\
& generic & Academic, Academic and Miscellaneous & & & \\
\hline Hansard & Specialised & Political Speeches & $1803-2005$ & $7,545,101$ & 1.6 billion \\
\hline
\end{tabular}

Table 1. Corpus data.

\section{Results and Discussion}

\subsection{The BNC}

A total of 438 tokens of IAT were retrieved from the BNC; 348 tokens in its contracted form (80\%) and 90 in its uncontracted form (20\%). Figure 1 shows the normalised distribution (per million words) in the different genres contained in the BNC. The highest frequency appears in the oral component (195 tokens). However, it should be noted that 107 occurrences of IAT out of the 243 tokens found in written genres appear in dialogues, which portrays it as a speech-based phrase. It is also worth noting that Fiction, Magazine and Newspaper have a higher rate of the contracted variant, another feature relating to the presence of oral features in written texts.

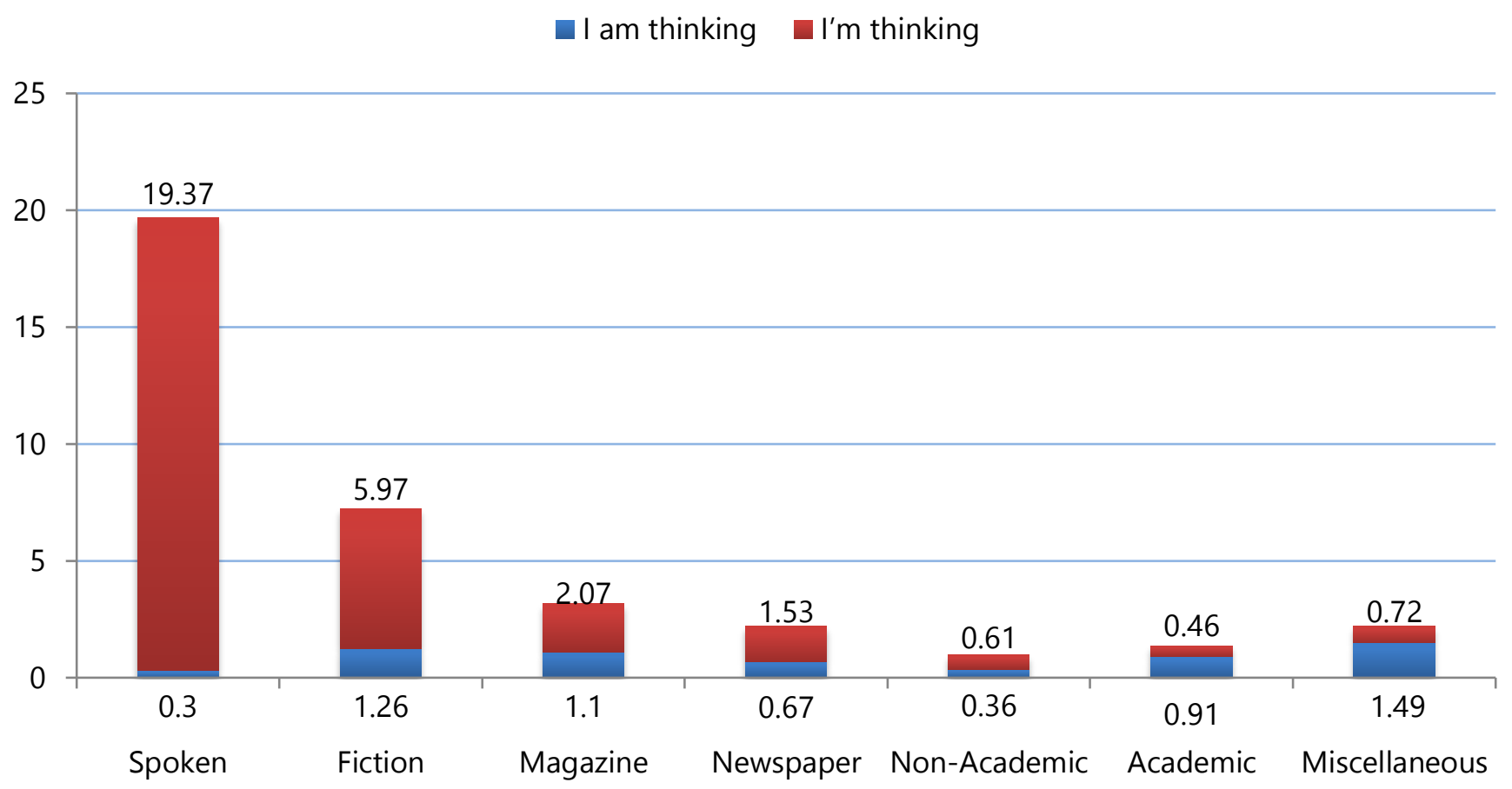

Figure 1. Distribution of IATS across genres in the BNC.

In what follows, I will analyse the examples found in this reference corpus in light of previous classifications (Huddleston \& Pullum 2002; Levin 2013). The results will then be contrasted with those from Hansard. It should be noted, however, that any classification must be treated with caution, since the progressive often implies 'multiple membership', as discussed in the literature review.

\subsubsection{Cogitate}


This class comprises uses where mental activity is the core meaning. This sense is the most frequent use in the BNC (286 tokens, 65.30\%). This cogitate meaning appears in intransitive and transitive clauses, (1)-(3) and (4), respectively. The reference is not necessarily restricted to the time of speaking, as in (1), (3) and (4); it can also report a habitual activity with the appropriate temporal reference, as in (2).

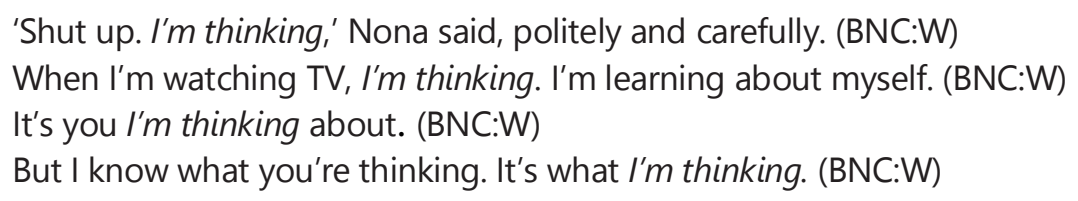

A mental active sense is also found in constructions with complement clauses - with or without that (24 examples), as in (5) and (6), respectively. As discussed in the literature review, for Nuyts (2001, p. 134) these constructions denote uncertainty 'with a tendency towards the positive'. Indeed in (5) the ironic tone of maybe reveals more certainty than uncertainty. However, the basic meaning in my corpus examples is better described in terms of mental activation triggered by immediate evidence (i.e. 'it just came to my mind'), rather than of uncertainty as illustrated in (5) and (6). This spontaneous expression of the speaker's attitude necessarily also implies a sense of uncertainty (it is not a stable mental act of evaluation), yet the core meaning here is the impromptu activation of a mental act, or rather its manifestation. This meaning arises from the basic notion of contingency (i.e. unpredictability) provided by the progressive construction.

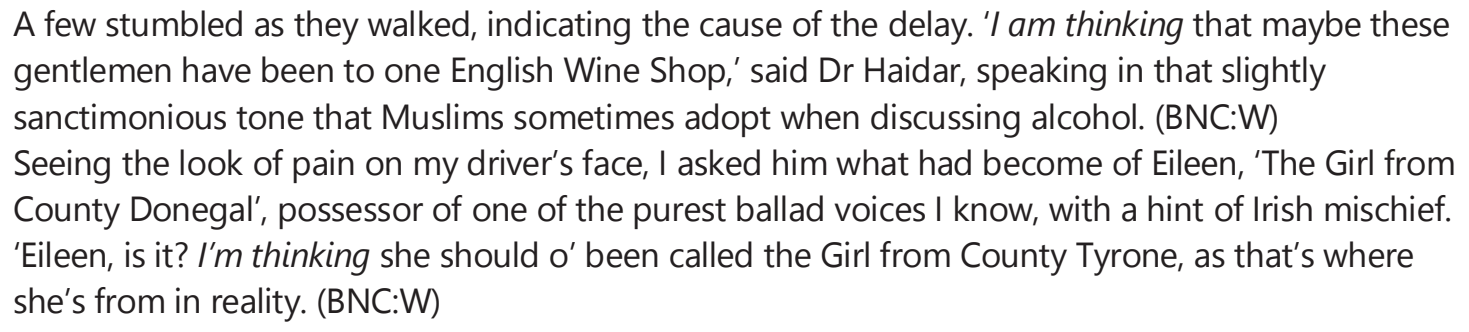

Mental activity is also the basic sense when IAT occurs with clausal complementation introduced by of (71 tokens) or about (3 tokens), as in (7). For Levin (2013, p. 221) these constructions denote future intentions in a hedged way. These future-oriented uses still denote mental activity, so there is no need to separate this class from the 'cogitate' group.

'Oh,' she said.' I'm thinking of doing that!' (BNC:W)

As regards hedging, the progressive inherently expresses contingency, as discussed in the literature review; therefore, IAT is always hedged to a certain point (i.e. it offers a provisional mental process). The sense of tentativeness is sometimes underlined by adverbs like perhaps or maybe, as in (8) and (9) below, but this sense overlaps with the cogitate propositional meaning.

'Ah, well then, perhaps I'm thinking of the word in a different way to you, because pathos to me means tender.' (BNC:W).

I'm thinking maybe I should be going myself.' (BNC:W)

\subsubsection{Parenthetical}

Only the hedged meaning seems to be present in a few examples of IAT (nine tokens) which function as 
comment clauses, (10)-(12). In these occurrences IAT serves a parenthetical function similar to the one ascribed to the simple form, I think. The most important distinguishing feature of these parentheticals is their ability to occur in medial or final position. These non-initial positions do not occur when the verb denotes mental activity.

That's nice too. All rich ones, good apartments / am thinking. And the ones closer... erm... down... inbet when, from the... (BNC:S)

Last Sunday the belated Lord Woodleigh and Miss Jilly Jonathan could not see the famous Blue Grotto on this island because Lord Woodleigh insisted to go to Mass in a church here. It was this, I am thinking, that made Miss Jonathan realize that if the marriage she was about to enter into with a man much different from herself, and older also, would not go well, she would never from a Catholic be obtaining a divorce. (BNC:W)

This is a rare opportunity to acquire a most valuable asset. 'I can see that for myself,' she reminded him, but suddenly her manner was more subdued, her words more cautious. 'But it's a long-term investment and, as I've only just explained, I haven't got that kind of capital. Besides, it won't come cheap, I'm thinking. (BNC:W)

\subsubsection{Interpretative}

Given the lack of consensus on the delimitation of the interpretative use, the term will be used here in its broadest sense. In this class I will include examples of IAT constructions which clarify any contiguous discourse segments, and not necessarily a simultaneous clause, as in the following examples:

Whilst there are, perhaps, many things to be celebrated about the 1960 s there are also many to be deplored. I am thinking, in particular, of the racist excesses of the mid to late sixties and beyond. (BNC:W)

This is the case of the Scandinavian countries - I am thinking of Finland and Iceland in particular. (BNC:W)

\subsubsection{Narrative}

This class comprises examples of IAT in which the speaker is conceived as a narrator who reports his/her past thoughts, as in (15) and (16).

$$
\begin{aligned}
& \text { All they could do was talk about their next movie, and I'm thinking, 'Have we finished this one?' } \\
& \text { (BNC:W) } \\
& \text { I've seen just about every kind of drunk, but I've never seen one shake like he did. It was more like } \\
& \text { a fit and I'm thinking oh, shit, how do I handle this? (BNC:W) }
\end{aligned}
$$

The use of the progressive here has been explained as an oral narrative device used to create a more vivid image in the mind of listeners and to foster a greater involvement of the experiencer (Biber et al. 1999, p. 475; Wright 1995, p. 470). The story unfolds as it is told, interweaving objective facts with inner thoughts. The speaker's emotional involvement is often emphasised by interjections, as in (17). The use of the progressive here alternates with the past forms was thinking or thought. In fact, Levin (2013, p. 210) illustrates his quotative class with a past progressive (When he said that stringent water-pollution standards would hinder industry, he was again thinking of Alaska and its abundance of clear rivers) and Nuyts $(2001$, p.116) presents this non-qualificational use of think introducing quotes with an example in the past tense (He thought: What the hell are they doing?). However, the 
use of the present makes the narrative more vivid, as if the subject-speaker-experiencer were recreating the experience as it is told.

$$
\text { I got home and it was like, glowing and I'm thinking oh my God! (BNC:S) }
$$

These narrative thoughts may also appear in final position, as parenthetical reporting constructions:

I sit on the wooden floor for a moment to gather my strength, also to decide exactly where I should take the relics to dispose of them. Somewhere far away, I'm thinking. (BNC:W)

\subsubsection{Filler}

Another singular use of IAT in the BNC arises in improvised speech. The expression typically appears in what Quirk et al. (1985) term 'nonsentences', (i.e. 'we cannot analyse them with confidence in terms of clause elements', p. 838) in co-occurrence with hesitation words and other filler phrases (e.g. erm, oh, mm, you know, yeah). This use often overlaps with other functions; yet, I have highlighted here seven examples in irregular sentences whose only function is to fill pauses and gain time to think, as illustrated in the following examples:

There should be an evening out, Yes, yes I mean it should work itself out. Yeah, sorry, I'm thinking of er Mm. You're looking at individuals Yeah, I was forgetting that that was that was calculated on the two. (BNC:S)

No I'm not gonna off, I can't hear it now I can, yeah Can didn't know they were coming up to stay Got that on the microphone but, ought does it? I'm thinking Oh, oh the way to reception, wedding reception mm I know I did Haven't got a clue I know what you're doing, I can tell by your face What? (BNC:S)

oh that's the work of er Oh yeah they can say the say the, say the names and the dates and the, yeah, mm Yeah and I'm thinking well yeah. I'm gonna have to do some work on this and then erm Yeah. when it just comes down to it and I just don't know where to start Mm. (BNC:S)

\subsubsection{Summary of functions of IAT}

Table 2 provides an overview of the five classes of IAT identified in the BNC, with raw frequencies and percentages. The most common use denotes active thinking, in line with Levin's (2013) data for all persons and tenses of think in the progressive. The 'cogitate' lexical meaning of the verb merged with the basic contingent meaning of the progressive discussed in the literature review conveys a sense of provisional, tentative thinking. There are, however, other uses of IAT with a faded lexical meaning serving a discourse function. One is its marginal use as a filler in improvised discourse to gain time to think what to say (seven tokens). A few other examples have been identified as parenthetical units, occurring in medial or final position (nine tokens). Lastly, there are two more productive uses, to wit, the interpretative and the narrative. The former is a cohesive device which clarifies a preceding segment; while the latter is a colloquial narrative technique which allows the speaker to talk about a situation prior to the time of speech, thus making it more vivid, as if it were perceptible through immediate cognition (i.e. the narrator re-experiences a past situation for a listener/reader).

\begin{tabular}{l|l|l}
\hline Type & Frequency & Percentage \\
\hline Cogitate & 286 & $65.30 \%$ \\
\hline Interpretative & 86 & $19.63 \%$ \\
\hline Narrative & 50 & $11.42 \%$ \\
\hline
\end{tabular}

Revista de Lenguas para Fines Específicos 24.2

ISSN: $2340-8561$ 


\begin{tabular}{l|l|l}
\hline Parenthetical & 9 & $2.05 \%$ \\
\hline Filler & 7 & 1.60 \\
\hline Total & 438 & $100 \%$ \\
\hline
\end{tabular}

Table 2. Classification of IAT in the BNC.

\subsection{Hansard}

Hansard contains 7161 tokens of IAT. Figure 2 shows the construction's distribution by decades in per million words, ${ }^{2}$ from six occurrences in 1880 to its highest peak in the 1960s (1389 tokens), before gradually decreasing over the following decades.

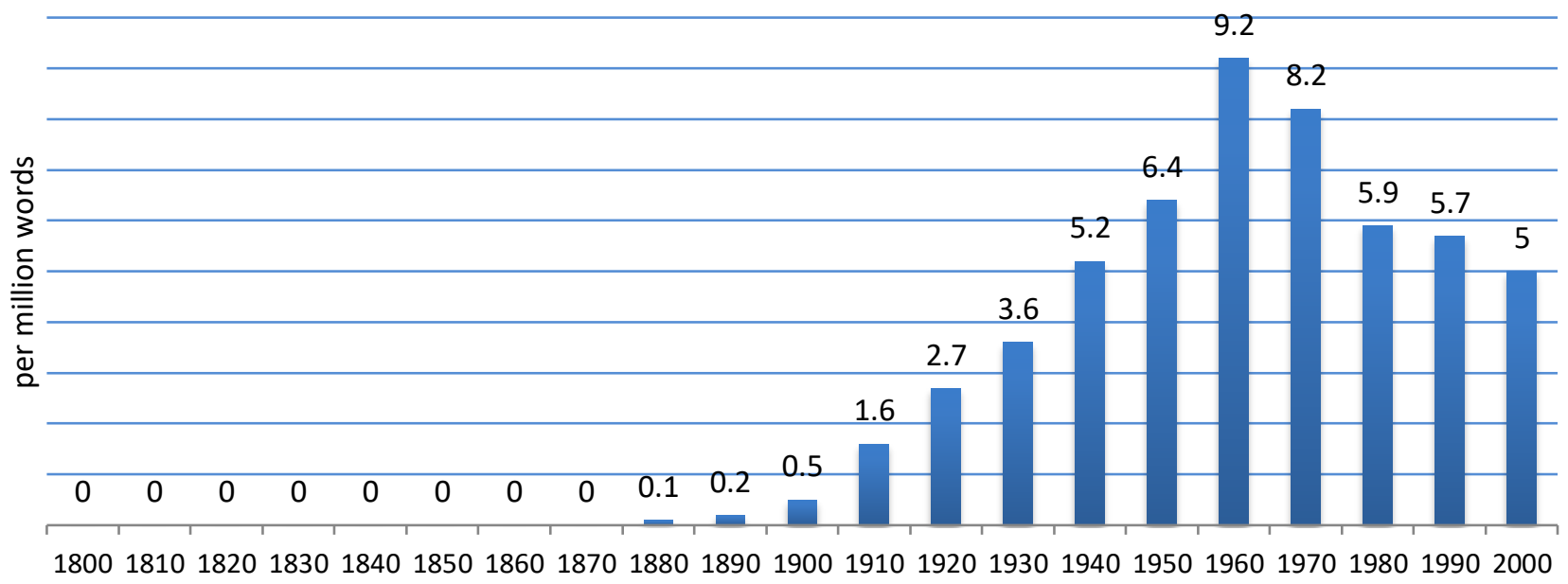

Figure 2. Normalised distribution of IAT in Hansard by decades.

IAT appears much more frequently in the spoken component of the BNC (19.67 pmw) than in Hansard. The latter shows a mean of 5.8 pmw in the period overlapping the sampling period of the BNC (1980s and 1990s). Although speeches represent spoken discourse, they belong to the category of texts 'written to be spoken'; therefore, they are carefully crafted texts, more formal and elaborate than conversation. Besides, they are 'monologic in nature', as observed by Smitterberg (2005, p. 232, n.22). As a matter of fact, Hansard contains only five examples of IAT in its contracted form (I'm thinking) - all occurring in quoted speech, as in (22) - while this shortened oral variant is the predominant form in the BNC (80\%).

'That's not very good,' the sentencer would say. 'I'm thinking of sending you to prison for quite a long time.' (H)

For the qualitative analysis of Hansard, I limited my investigation to the texts produced in the last decade (19952005). The total sum of 823 tokens retrieved was analysed and classified into the types identified in the BNC.

Raw numbers for each decade are supplied here in parentheses: 1880 (6), 1890 (9), 1900 (32), 1910 (131), 1920 (189), 1930 (340), 1940 (471), 1950 (761), 1960 (1389), 1970 (1323), 1980 (1084), 1990 (997), and 2000 (429). It should be noted that the data corresponding to the 2000s are only for the first five years, since Hansard only extends to 2005. 
Within this data set, there were no examples of IAT used as a filler or parenthetical phrase, which is unsurprising since these functions occur in conversation, not in planned speech. Only one example of narrative IAT was found:

So I am thinking, 'Ha, I am not going to go mad like the rest of them. I am okay. I am taking vitamin tablets.' (H)

The frequency of IAT denoting cogitation in Hansard was surprisingly low (49 tokens, 5.95\%), as opposed to the BNC (65.30\%). Beside a few fixed collocations (e.g., think on one's feet, or think aloud), IAT appeared in intransitive use, as in (24), (25) and (26), the last two in an intentional sense (Levin 2013, p. 221) with the prepositions of and about. IAT also occurred in transitive clauses complemented by a that clause, as in (27).

I should stress that I am thinking from my own personal point of view. $(\mathrm{H})$

I am thinking about taking the currency out of the exchange rate mechanism. $(\mathrm{H})$

The experience of resigning has been so pleasant that I am thinking of recommending it more widely. $(\mathrm{H})$

Given my anger at what has happened to my constituents, I am thinking, first, that I do not want to use unparliamentary language and secondly, that even Labour politicians are basically decent human beings. $(\mathrm{H})$

The most striking result to emerge from the qualitative analysis is how it was overwhelming used in an interpretative sense (773 tokens 93.92\%). The results of the qualitative distribution in the BNC and Hansard in percentage terms can be compared in Figure 3.

BNC Hansard

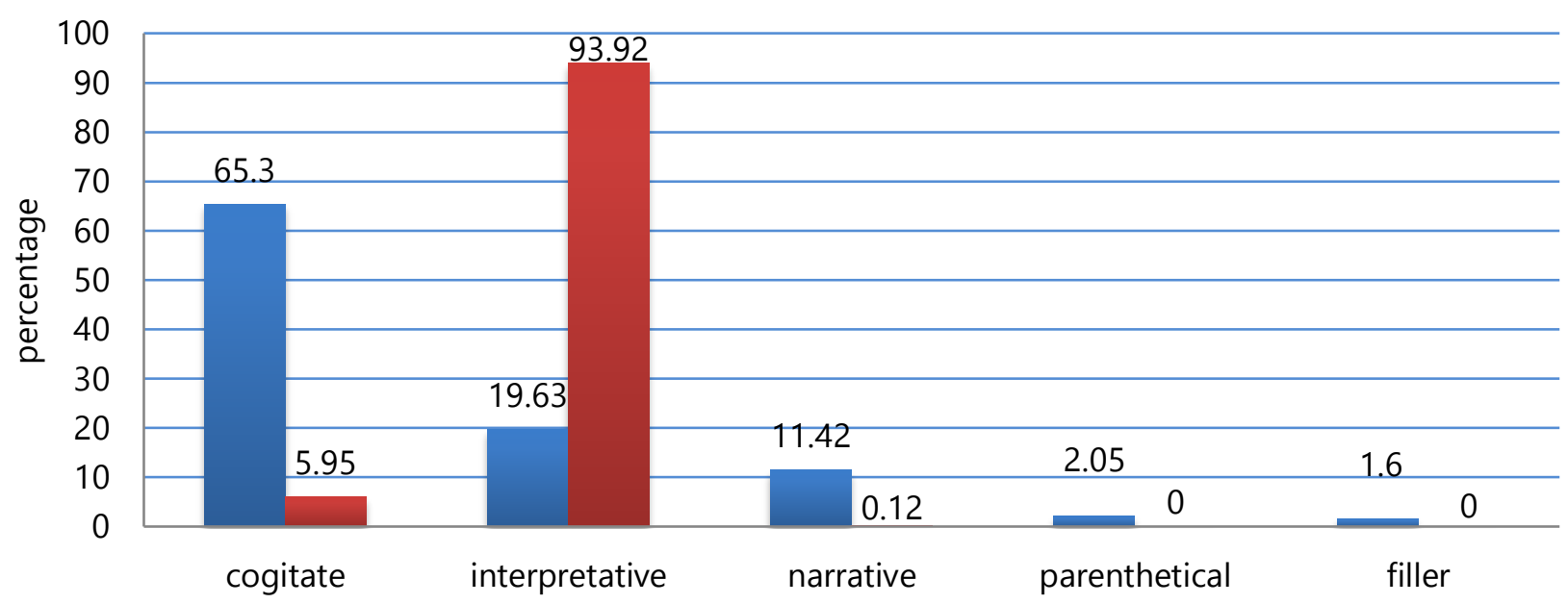

Figure 3. Classification of IAT in the BNC and Hansard.

The overwhelming predominance of the interpretative use of IAT in political speeches merits a finer-grained analysis. Speakers use IAT as a clarifying device to help listeners interpret their words by drawing attention to a previous utterance and offering clarification. However, as regards the interpretive use of IAT in my Hansard sample only eight tokens can be regarded as prototypical, according to the criteria summarised in Smith and Leech (2013, p. 91) discussed in Section 2.2. For example, (28) and (29) contain two simultaneous clauses in a syntactic frame, with co-referential agentive subjects, in which the IAT clause reinterprets the preceding one. 
Interestingly enough, IAT was also used for cataphoric reference, as in (30) in which the interpreted clause follows the interpretation.

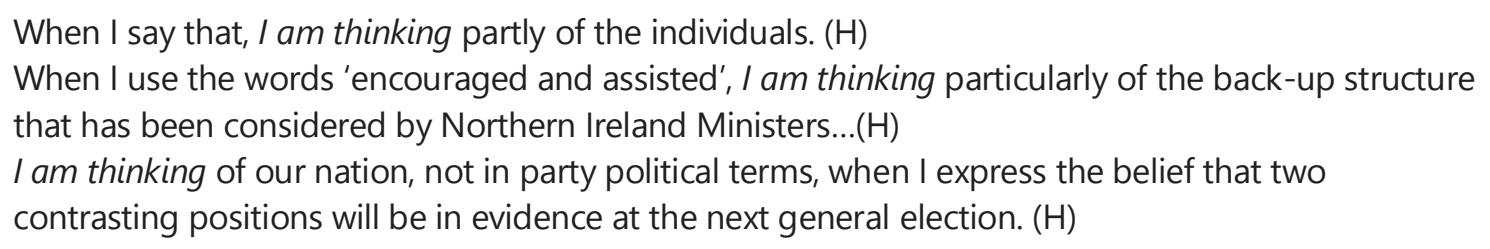

The interpretation in the last example (I am thinking of our nation) is followed by a negative explanation (not in party political terms) which, as noted by Smitterberg (2005, p. 232), explains through exclusion rather than invitation. However, a negative IAT may also offer an inclusive explanation (i.e. 'not only') as in (31). ${ }^{3}$ Another rhetorical pattern detected in the data includes both an exclusive and an inclusive explanation, as in (32).

$$
\begin{aligned}
& \text { But in protecting children we must also be sure that others involved in the justice system are able } \\
& \text { to gain access to the information that they need to protect children and support their parents-I } \\
& \text { am thinking not only of Members of Parliament, but of others such as the police, the Crown } \\
& \text { Prosecution Service, parents, litigants in person and organisations that work to assist them. (H) } \\
& \text { My Lords, I do not believe that any of the candidates for the assembly of whom I am aware have } \\
& \text { had any experience whatever of European negotiations. I am not speaking about Conservative } \\
& \text { candidates. I am thinking of all the other candidates of whom I know to date. (H) }
\end{aligned}
$$

Besides exclusion, other types of interpretations have been detected. Sometimes the IAT clause provides an example by way of illustration. In other cases, it modifies its antecedent by widening or restricting its scope of reference. Accompanying adverbials often give clues about the specific meaning and function of the explanation. Table 3 shows the most frequent words co-occurring with IAT in Hansard (raw frequencies and mutual information (MI) score).

\begin{tabular}{c|c|c|c|c}
\hline Word & Frequency & All & \% & MI \\
\hline particularly & 251 & 85021 & 0.30 & 7.48 \\
\hline especially & 108 & 54542 & 0.20 & 6.90 \\
\hline particular & 188 & 102937 & 0.18 & 6.79 \\
\hline example & 46 & 109679 & 0.04 & 4.66 \\
\hline here & 29 & 76636 & 0.04 & 4.52 \\
\hline
\end{tabular}

Table 3. Five most frequent collocates in Hansard (within three words to the right).

Among the most recurrent collocates with IAT are particularisers (e.g. particularly, especially) and appositive conjuncts (e.g. for example). ${ }^{4}$ The former serve a restrictive function, as illustrated in (35), where the interpreted

3 Although my corpus sample does not contain combinations with an intermedial word between the auxiliary and the lexical verb, a search for I am not thinking in Hansard for the period 1996-2005 yielded 26 results (e.g. Does the Minister further agree that the Better English Campaign, so admirably led by Mr. Trevor McDonald, would do well to concentrate its attention on English in a relatively public role - I am not thinking of radio and television but of railway station announcements and telephonists responding to outside calls).

$4 \quad$ Quirk et al. (1985, p. 604) identify two classes of restrictive subjuncts: exclusives and particularisers, depending on whether they limit the application of the utterance exclusively or predominantly to the focused part. Appositive conjuncts rephrase the content of the preceding segment $(1985$, p. 637). 
part 'some' is primarily limited to 'the Leader of the Opposition'; the latter offers clarification with an example, which is included in the reference of the focused element as in (36).

I do not say that a complete parallel should be drawn with the past, although some would do well not to overlook it. I am thinking particularly of the Leader of the Opposition. $(\mathrm{H})$

There are those who know that I have been responsible for regulations that did not provide for compensation. I am thinking, for example, of the head deboning prohibitions that we imposed as part of the BSE requirements. There are many other examples... $(\mathrm{H})$

Anaphoric textual deictics, such as here, also accompany IAT to build cohesion with the interpreted part:

We need to improve and enhance our management of the Territorial Army. I am thinking here of mobilisation procedures which at present are ad hoc, and need to be... $(\mathrm{H})$

In sum, IAT is mostly used in political speeches as a discourse or pragmatic marker; its function is to 'express the relation or relevance of an utterance to the preceding utterance or to the context' (Brinton 1996, p. 30). The verb loses its propositional meaning and gains a discursive function. Actually, in this interpretative use IAT is often optional insofar as it can be replaced by other discourse markers (e.g. particularly, for example) or by punctuation marks (e.g. semicolon or pauses in speech):

People who are troubled by the fear of large council tax increases_ Lam thinking particularly of pensioners living on fixed incomes_- will appreciate that this Government have taken... $(\mathrm{H})$

Without its propositional meaning IAT becomes a useful structuring device of spoken language which allows the speaker to focus on the precise element he/she wishes to elaborate on. This function clearly contrasts with the cogitate sense of think in the progressive, which expresses uncertain or tentative thinking processes.

The cogitate and interpretative uses identified in Hansard have been classified into different groups: the former with its full lexical meaning; and the latter with a discursive function fading its lexical cogitate sense. Nevertheless, it is important to bear in mind that both embrace the core notion of contingency basically provided by the progressive. De Wit and Brisard $(2014$, p. 86) claim that the interpretative progressive is used to clarify a singular event, which is 'not entirely obvious' and 'not consolidated in the current circumstances', thus linking this use to the other meanings of the progressive under the umbrella notion of contingency. The interpretative use of IAT focuses on a singular discourse segment and serves a performative function ${ }^{5}$ (i.e. it is valid at the moment of speaking), which identifies it as a unique mental expression. As Nuyts (2001) suggests, 'bringing up one's commitment, of any type, to a state of affairs in a discourse implies that the status of the state of affairs in this regard is not obvious, e.g. because the hearer turns out to hold a different view, or because there is otherwise new information relevant for one's view' (p. 363, emphasis mine). The basic meaning supplied by the progressive in these interpretative uses is contingency (i.e. it applies to a specific 'here and now' utterance, which is not applicable to other situations). The cogitate use of IAT offers another contingent interpretation: it reports provisional, tentative mental activity.

\section{Concluding remarks}

\footnotetext{
5 I have taken the definition of performativity from Nuyts (2001, p. 309): 'speaker commitment at the moment of speaking.'
} 
This paper has explored the frequency and use of IAT in contemporary British English general texts and political speeches. The study was designed to determine to what extend genre influences the use and distribution of this progressive construction. In light of the findings from I think and the contingent meaning of the progressive discussed in the literature review, it was hypothesised that IAT would show a different use and distribution across genres.

The analysis of IAT in a general corpus has revealed that besides a major cogitate meaning, which accounts for $65 \%$ of its occurrences, the construction also serves four other discourse-oriented functions: two minor dialogic uses - as comment clauses and as fillers - a narrative device for quoting thoughts and an explanatory function.

One of the most significant findings to emerge from the analysis of IAT in parliamentary speeches is its almost exclusive function as a discourse marker in this genre. The analysis of more than 800 examples of IAT in political speeches reveals a central cohesive function: speakers seek to ensure clarity in their speech by extending their arguments with an utterance that clarifies a previous string of discourse. This use derives from the interpretative use of the progressive. Some IAT clauses behave as prototypical interpretatives, meeting all the criteria summarised in Smith and Leech (2013, p. 91): the interpreted part and the interpretation appear in a syntactic frame and occur simultaneously with co-referential agentive subjects, and the interpretation contains a speech act (illocutionary/mental) verb. However, the examination of the interpreted utterances has shown that most uses of IAT only focus on a segment of the previous context, and the reporting verb in the interpreted part, which would be redundant in this speech context, is missing.

The corpus analysis has also revealed the presence of neighbouring adverbials which reinforce or round off the meaning and function of IAT. These accompanying cohesive devices render the IAT construction redundant; to the point that it can be omitted without losing the clarifying sense. The interpretation may involve a restriction, addition or reformulation of the interpreted element. The most frequent role of the IAT clause is to restrict the scope of the interpreted element, strengthened by the use of 'particularisers', such as particularly or especially.

The evidence from this study suggests that in a specialised language, like that of political speeches, IAT loses its propositional cogitate basic meaning ('I have an opinion', 'I am using my mind') and functions as a discourse device. This could reveal an ongoing process of grammaticalisation (i.e. 'the change whereby lexical items and constructions come in certain linguistic contexts to serve grammatical functions and, once grammaticalized, continue to develop new grammatical functions' (Hopper \& Traugott 2003, p. 18)). Indeed, IAT has extended its range of functions beyond its original cogitate meaning. Nonetheless, the decreasing tendency observed in Hansard (Figure 2) could work against a grammaticalisation hypothesis, since grammaticalisation typically implies an increase in frequency. A qualitative diachronic analysis would be required to determine whether all the uses of IAT are declining or if this trend only affects some of its functions. Further research with additional diachronic data would be necessary to determine its evolution.

At a more general level, the findings presented here have confirmed that the basic meaning of the progressive is modal, rather than aspectual, as proposed by De Wit and Brisard (2014). All the uses of IAT evaluated in this study are linked by the notion of contingency, which confirms that the interpretation of the progressive is greatly affected by contextual information. Further research needs to examine the increasing use of the progressive with other stative verbs in order to establish a greater degree of accuracy on this matter. 


\section{About the author}

Montse Martínez Vázquez is Professor of Linguistics in the Department of Philology andTranslation at the Pablo de Olavide University in Seville (Spain). Her research focuses on contrastive linguistics and recent grammatical change.

\section{References}

Martínez Vázquez, M. (2018. I'm loving it! A Corpus-Based Study of the Progress of love. Journal of English Linguistics 42(2). 140-166.

Aarts, B., Close, J. \& Wallis, S. (2010). Recent changes in the use of the progressive construction in English. In B. Cappelle \& N. Wanda (Eds.), Distinctions in English grammar offered to Renaat Declerck (pp. 148-167). Tokyo: Kaitakusha.

Aijmer, K., (1997). I think -an English modal particle. In T. Swan \& O. JansenWestvik (Eds.), Modality in the Germanic Languages (pp. 1-7). Berlin: de Gruyter Mouton.

Alexander, M. \& Davies, M. (2015-) Hansard Corpus 1803-2005. Available online at http://www.hansard-corpus.org.

Biber, D., Johansson, S., Leech, G., Conrad, S., \& Finegan, E. (1999). Longman grammar of spoken and written English. Harlow: Pearson.

Brinton, L. J. (1996). Pragmatic markers in English: Grammaticalization and discourse functions. Berlin: de Gruyter Mouton.

Brinton, L. J. (2008). The comment clause in English: Syntactic origins and pragmatic development. Cambridge: Cambridge University Press.

Bybee, J. (2015). Language change. Cambridge: Cambridge University Press.

Calver, E. (1946). The uses of the present tense forms in English. Language 22(4). 317-325.

Comrie, B. (1976). Aspect. Cambridge: Cambridge University Press.

De Wit, A. \& Brisard, F. (2014). A Cognitive Grammar account of the semantics of the English present progressive. Journal of Linguistics 50(1). 49-90.

Downing, A. (2015). English grammar: A university course. London: Routledge.

Goldsmith, J. \& Woisetschlaeger, E. (1982). The logic of the English progressive. Linguistic Inquiry 13(1). 79-89.

Hopper, P. J. \& Traugott, E.C. (2003). Grammaticalization. Cambridge: Cambridge University Press.

Huddleston, R., \& Pullum, G.K. (2002). The Cambridge grammar of the English language. Cambridge: Cambridge University Press.

Jucker, A. (1986) News interviews. Amsterdam: John Benjamins.

Kaltenböck, G. (2009). Initial I think: Main or Commment clause? Discourse and Interaction 2(1), 49-70.

Kaltenböck, G. (2010). Comment clauses as constructions. Vienna English Working Papers 19(1,2). 21-46

Revista de Lenguas para Fines Específicos 24.2

ISSN: 2340-8561 
Kärkkäinen, E. (2003). Epistemic Stance in English Conversation: A Description of its Interactional Functions, with a Focus on I think. Amsterdam: John Benjamins.

Kirk, J.M. (2015). The progressive in Irish English: Looking both ways? In P. Collins (Ed.), Grammatical Change in English World-Wide (pp.87-118). Amsterdam: John Benjamins.

König, E. (1980). On the context-dependence of the Progressive in English. In C. Rohrer (Ed.), Time, Tense, and Quantifiers. Proceedings of the Stuttgart Conference on the Logic of Tense and Quantification (pp. 269-291). Tübingen: Niemeyer.

König, E. (1995). He is being obscure: non-verbal predication and the progressive. In Bertinetto, P.M., Bianchi, V., Dahl, O. \& Squartini, M. (Eds.), Temporal Reference, Aspect, and Actionality. Vol. Il: Typological Approaches (pp. 155-167). Turin: Rosenberg \& Sellier.

Kranich, S. (2010). The progressive in Modern English: A corpus-based study of grammaticalization and related changes. Amsterdam: Rodopi.

Brinton, L.J. (1996). Pragmatic Markers in English. Grammaticalization and Discourse Functions. Berlin: Mouton de Gruyter.

Leech, G. (2004). Meaning and the English verb, 3rd edn. London: Longman.

Leech, G., Hundt, M., Mair, C. \& Smith, N. (2009). Change in contemporary English: A grammatical study. Cambridge: Cambridge University Press.

Levin, M. (2013). The progressive verb in modern American English. In B. Aarts, J. Close \& Wallis, S. (eds.), The verb phrase in English: Investigating recent language change with corpora (pp. 187-216). Cambridge: Cambridge University Press.

Ljung, M. (1980). Reflections on the English progressive. Gothenburg: Acta Universitatis Gothoburgensis.

Nuyts, J. (2001). Epistemic Modality, Language, and Conceptualization. A Cognitive-Pragmatic Perspective. Amsterdam: Benjamins.

Quirk, R., Greenbaum, S., Leech, G. \& Svartvik, J. (1985). A comprehensive grammar of the English language. London: Longman.

Scheffer, J. (1975). The progressive in English. Amsterdam: North-Holland.

Simon-Vandenbergen, A.M. (1998). Modal (un)certainty in political discourse: a functional account. Language Sciences, 19(2), 341-56.

Simon-Vandenbergen, A.M. (2000). The functions of I think in political discourse. Journal of Applied Linguistics, 10, 41-63.

Smith, N. (2005). A Corpus-based Investigation of Recent Change in the Use of the Progressive in British English. Unpublished Doctoral Dissertation. Lancaster University.

Smith, N. \& Leech, G. (2013). Verb structures in twentieth-century British English. In B. Aarts, J.Close \& S. Wallis (Eds.), The verb phrase in English: Investigating recent language change with corpora (pp. 68-98). Cambridge: Cambridge University Press.

Smitterberg, E. (2005). The progressive in 19th century English: A process of integration. Amsterdam: Rodopi.

Thompson, S. A.; Mulac, A. (1991). A quantitative perspective on the grammaticalization of epistemic parentheticals in English. In E.C. Traugott, B. Heine (Eds.), Approaches to grammaticalization Vol. 2 (pp. 313-339.) Amsterdam: Benjamins,

Urmson, J.O. (1952). Parenthetical verbs. Mind 61. 480-496.

Van Bogaert, J. (2010). A constructional taxonomy of I think and related expressions: Accounting for the variability of complement-taking mental predicates. English Language and Linguistics, 14(3), 399-427.

Van Bogaert, J. (2011). I think and other complement-taking mental predicates: A case of and for constructional grammaticalization. Linguistics, 49(2), 295-332. 
Van Bogaert, J. (2006). "I guess, I suppose and I believe as pragmatic markers: Grammaticalization and functions". Belgian Journal of English Language and Literatures, 4, 129-49.

Williams, C. (2001). The progressive form and the non-progressive form in English: The theory of susceptibility to change. Cauce, Revista de Filología y su Didáctica, 24, 87-117.

Wright, S. (1995). The mystery of the modal progressive. In D. Kastovsky (Ed.), Studies in Early Modern English (pp. 467-485). Berlin: de Gruyter Mouton. 